\title{
Experimental Investigation on Thermal Dielectric Characterization for New PMMA Nanocomposites
}

\author{
Ahmed Thabet \\ Faculty of Energy Engineering, Nano-Technology Research Centre, \\ Aswan University, Aswan, EGYPT
}

\begin{abstract}
Nanostructured materials are attracting interests and applications, thus; physical and electrical properties of Polymethylmethacrylate (PMMA) nanocomposite materials under various thermal conditions are currently being studied. The dielectric behavior of new nanocomposite materials of Polymethylmethacrylate filled with nanoclay or nano-fumed silica has been measured at various frequency $(0.1 \mathrm{kHz}-1 \mathrm{kHz})$ and temperatures $\left(20^{\circ} \mathrm{C}-60^{\circ} \mathrm{C}\right)$. Dielectric spectroscopy has been used to characterize ionic conduction and state the effect of filler concentration on the dielectric permittivity and dielectric losses, therefore; the relative permittivity and the loss tangent are measured by dielectric spectroscopy for Polymethylmethacrylate with and without nanofillers. Finally, it has been compared between dielectric properties of new Polymethylmethacrylate nanocomposites which prepared by adding nanofillers of clay or fumed silica with different concentrations under various temperatures.
\end{abstract}

Keywords: Polymethylmethacrylate, Dielectric properties, Nano-composite, Nanoparticles, Polymers, Thermal characterization.

\section{Introduction}

Polymethylmethacrylate (PMMA) is a versatile polymeric material that is well suited for many microelectronic applications. It is often preferred because of its moderate properties, easy handling and processing, and low cost. Its melting point it $160^{\circ} \mathrm{C}$. Also, Polymethylmethacrylate is one of the most versatile polymeric materials that are well suited for many applications in micro electric and electro-optics areas. This polymer offers low costs, process ability, possibility of functionalization, and are semiconductor nanoparticles, which simultaneously show a size-dependent band gap shift, high carrier mobility, and nonlinear optical properties [1-5]. Fillers are used in polymeric dielectric materials for improving specific electrical and other properties, or for controlling costs. However conventional micro-sized fillers generally impact the electric strength of polymeric materials negatively. Recent applications have shown that composite dielectrics with nanosized fillers may exhibit more attractive electrical characteristics [6-10]. One of the advantages of nanometric fillers is their large specific surface area when compared with micronsized fillers.

A high surfactant concentration can also compromise the adsorption of the matrix polymer chains on the filler particles, so it is necessary to establish a balance between matrix adsorption and the dispersion of the particles [11]. Thus, nanotechnologies can have a powerful impact on the development of advanced electric and electronic products. In the case of polymer nanocomposites a few percent of functional nanofillers are sufficient to significantly modify polymer behavior, as regards mechanical, chemical, environmental and electrical properties. In contrast to conventional filled polymers, nanocomposites are composed of nanometer sized fillers, which are homogenously distributed within the polymer matrix [12-18].

Nowadays, dielectric materials of nano scale dimensions have aroused considerable interest. It is mention two examples. First, in the semiconductor industry, in order to keep pace with Moore's law scaling, the thickness of the gate oxide dielectric material is reaching nanoscale dimensions $[19,20]$. Second, the high energy density capacitors industry is currently

Received: March $30^{\text {th }}, 2014$. Accepted: November $10^{\text {th }}, 2014$ 
considering dielectric composites with a polymer host matrix filled with inorganic dielectric nanoparticles or polarizable organic molecules [21-27]. Work is underway to examine thermal electric and dielectric properties of nanocomposite materials composed of nanoparticles and their compounds stabilized within a polymeric dielectric matrix.

In this paper, Polymethylmethacrylate nanocomposites have attracted wide interest in regard to enhancing their properties and extending their utility. The electric and dielectric properties of PMMA nanocomposite materials have been demonstrated to be highly dependent on the size, structure, and concentration of the nanoparticles, as well as on the type of polymeric matrix. Significant efforts have been devoted for improving the dielectric properties of nanocomposites by nanosized filler within the polymer. Therefore, it has been concerned in this paper the effect of types of costless nanofillers on electrical properties of polymeric nanocomposite under various thermal temperatures. All experimental results of dielectric spectroscopy have been measured and compared to detect all effects of nanofillers on dielectric properties of polymethylmethacrylate nanocomposite industrial materials.

\section{Experimental Setup}

HIOKI 3522-50 LCR Hi-tester device has been measured nanocomposite electrical parameters: $|\mathrm{Z}|,|\mathrm{Y}|, \theta, \mathrm{Rp}(\mathrm{DCR})$, Rs (ESR, DCR),G, X, B, Cp, Cs, Lp, Ls, D (tan $\delta$ ), at variant frequencies. Specification of LCR is Power supply: 100, 120, 220 or $240 \mathrm{~V}( \pm 10 \%)$ AC (selectable), 50/60 Hz, Frequency: DC, $1 \mathrm{mHz}$ to $100 \mathrm{kHz}$, Display Screen: LCD with backlight / 99999 (full 5 digits), Basic Accuracy: $Z: \pm 0.08 \%$ rdg. $\theta: \pm 0.05^{\circ}$, and External DC bias $\pm 40 \mathrm{~V}$ max.(option) (3522-50 used alone $\pm 10 \mathrm{~V}$ max./ using $9268 \pm 40 \mathrm{~V}$ max.). Thus, it has been measured all dielectric properties for pure and nanocomposite industrial materials by using HIOKI 3522-50 LCR Hi-tester device. Figure 1 shows HIOKI 3522-50 LCR Hi-tester device for measuring characterization of nanocomposite insulation industrial materials. The industrial materials studied here is Polymethylmethacrylate which has been formulated utilizing variant percentages of nanoparticles of cay and fumed silica. The base of all these polymer materials is commercially available and already in use in the manufacturing of highvoltage (HV) industrial products and their properties detailed are given in table 1.

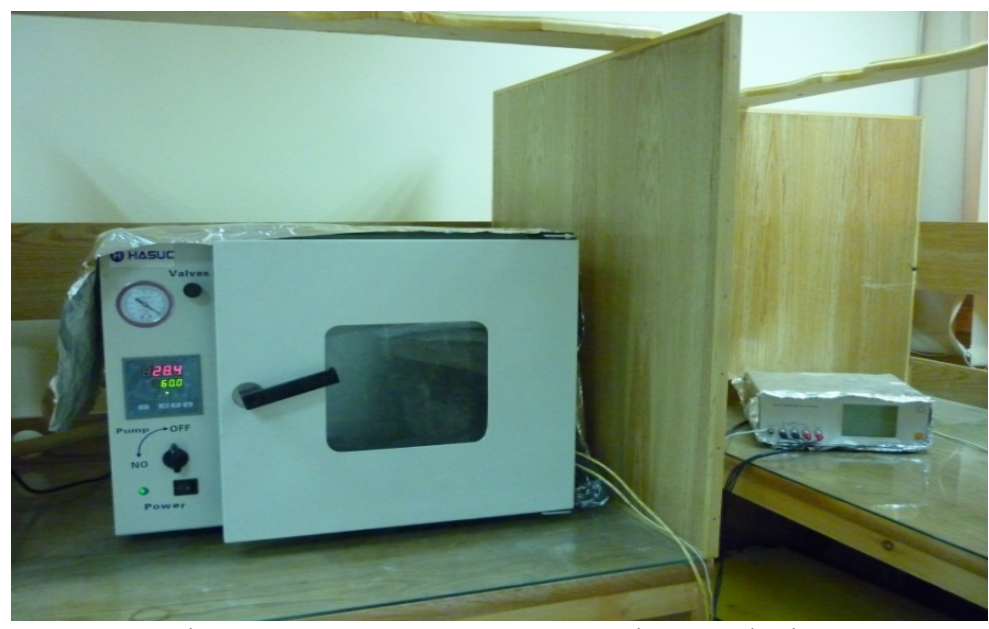

Figure 1. HIOKI 3522-50 LCR Hi-tester device

Additives of clay and fumed silica nanoparticles to the base industrial polymers have been fabricated by using mixing, ultrasonic, and heating processes under using SOL-GEL method. The distribution of nanoparticles within polymer matrix has been detected by using scanning electron microscope (SEM) as shown in figure 2. 
Table 1. Dielectric Properties Of Pure And Nano-Composite Materials

\begin{tabular}{lll}
\hline \hline Materials & $\begin{array}{l}\text { Dielectric } \\
\text { Constant at } \\
\mathbf{1 k H z}\end{array}$ & $\begin{array}{l}\text { Resistivity } \\
(\mathbf{\Omega} . \mathbf{m})\end{array}$ \\
\hline Pure PMMA & 3.3 & $10^{13}$ \\
PMMA + 1\%wt Clay & 3.23 & $10^{15}$ \\
PMMA + 5\%wt Clay & 2.89 & $10^{15}-10^{17}$ \\
PMMA + 10\%wt Clay & 1.86 & $10^{17}-10^{20}$ \\
PMMA + 1\%wt Fumed Silica & 3.34 & $10^{12}$ \\
PMMA + 5\%wt Fumed Silica & 3.89 & $10^{12}-10^{10}$ \\
PMMA + 10\%wt Fumed & 4.19 & $10^{10}-10^{8}$ \\
Silica & & \\
\hline \hline
\end{tabular}

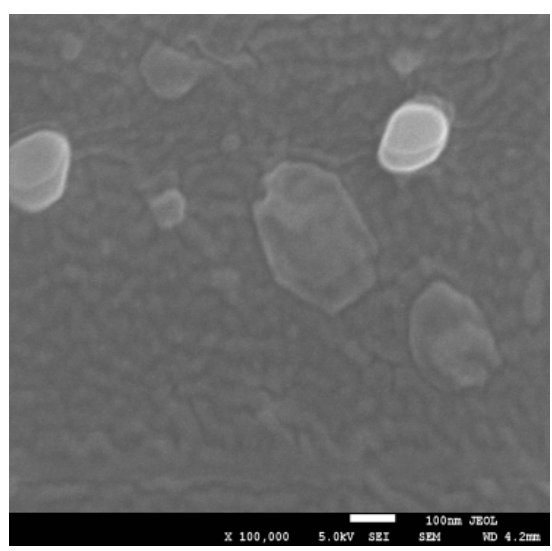

(a) Clay/PMMA

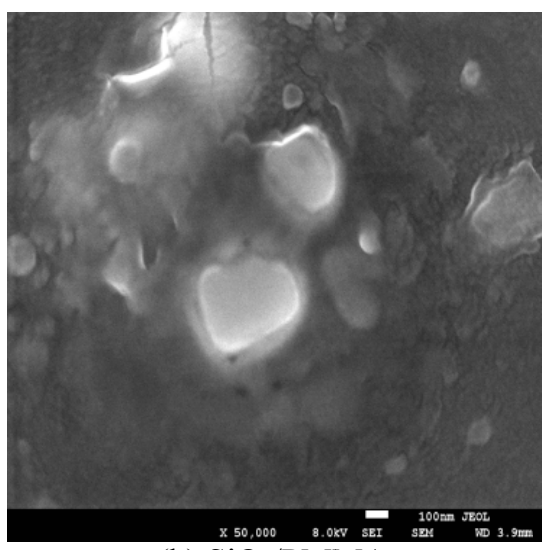

(b) $\mathrm{SiO}_{2}$ /PMMA

Figure 2. SEM images for PMMA nanocomposites at room temperature $\left(20^{\circ} \mathrm{C}\right)$

Thus, preparations of the studied Polymethylmethacrylate nanocomposites have been used SOL-GEL method; the sol-gel processing of the nanoparticles inside the polymer dissolved in non-aqueous or aqueous solution is the ideal procedure for the formation of interpenetrating networks between inorganic and organic moieties at the milder temperature in improving good compatibility and building strong interfacial interaction between two phases. Sol-gel process has been used successfully to prepare nanocomposites with variant nanoparticles in a range of polymer matrices. Several strategies for the sol-gel process are applied for formation of the 
hybrid materials. One method involves the polymerization of organic functional groups from a preformed sol-gel network. The sol- gel process is a rich chemistry which has been reviewed elsewhere on the processing of materials from glass to polymers. The organic-inorganic hybrid nanocomposites comprising of polymer, and nanoparticles were synthesized through sol-gel technique at ambient temperature [28].

\section{Results and Discussion}

Dielectric Spectroscopy is a powerful experimental method to investigate the dynamical behavior of a sample through the analysis of its frequency dependent dielectric response. This technique is based on the measurement of the capacitance as a function of frequency of a sample sandwiched between two electrodes. The tan $\delta$, and capacitance (C) were measured as a function of frequency in the range $0 \mathrm{~Hz}$ to $1 \mathrm{kHz}$ at variant temperatures for all the test samples. The measurements were made using high resolution dielectric spectroscopy.

\section{A. Characterization of PMMA Nanocomposites at Room Temperature $\left(20^{\circ} \mathrm{C}\right)$}

Figure 3 shows loss tangent versus frequency for Clay/ PMMA nanocomposites at room temperature $\left(20^{\circ} \mathrm{C}\right)$. The loss tangent decreases with increasing the percentage of clay nanoparticles percentage up to certain value $(5 \% \mathrm{wt}$.), specially, at low frequencies but it increases with increasing clay nanoparticles percentage up to certain value $(10 \% \mathrm{wt}$.), specially, at high frequencies. As shown in

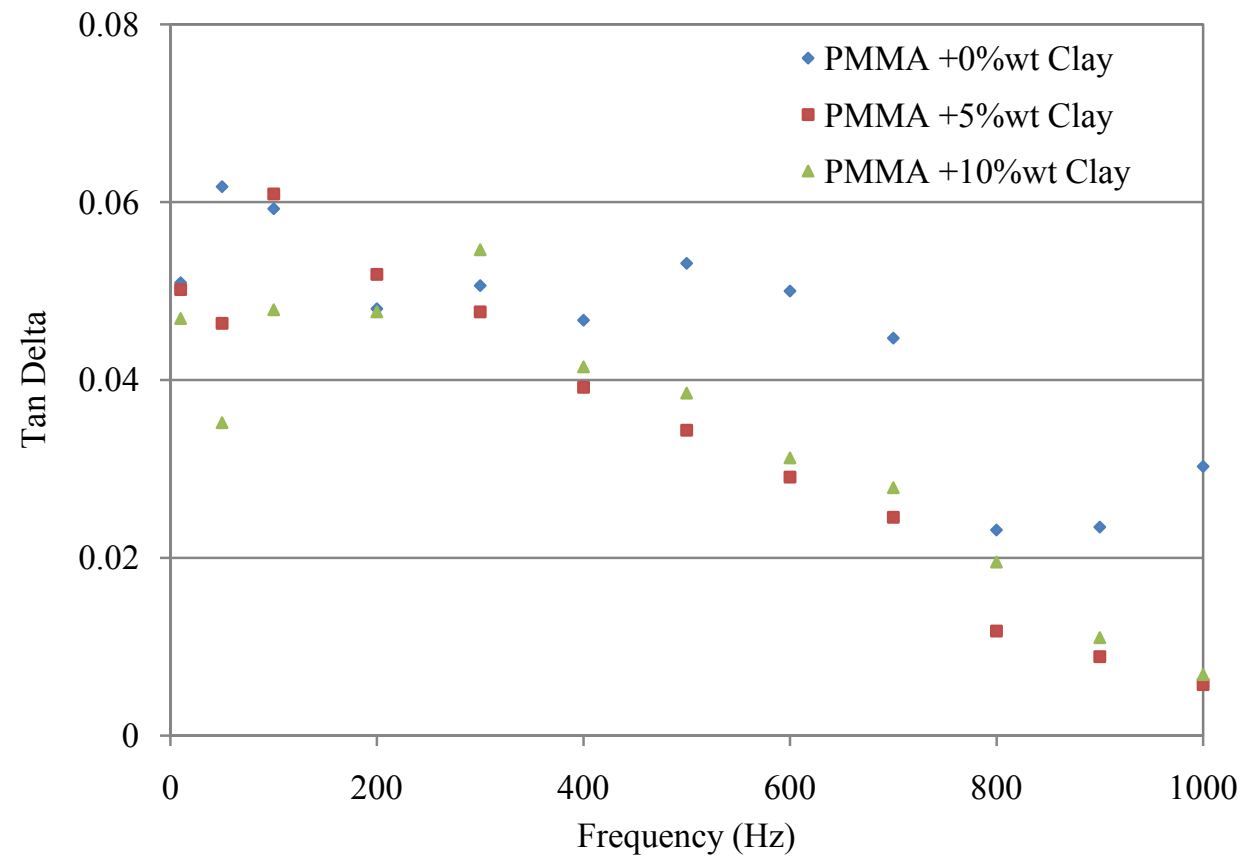

Figure 3. Measured loss tangent of Clay/PMMA nanocomposites at room temperature $\left(20^{\circ} \mathrm{C}\right)$

Figure 4, the measured loss tangent decreases with increasing percentage of fumed silica nanofillers in PMMA nanocomposite up to certain value (10\%wt.) especially at room temperature $\left(20^{\circ} \mathrm{C}\right)$. On the other wise, figure 5 contrasts on capacitance of Clay/PMMA nanocomposites as a function of frequency at room temperature $\left(20^{\circ} \mathrm{C}\right)$. The measured capacitance decreases with rising the percentage of clay nanofillers in the nanocomposite up to certain value $(5 \%$ wt.) but it increases with increasing clay percentage nanofillers up to percentage (10\%wt.). 


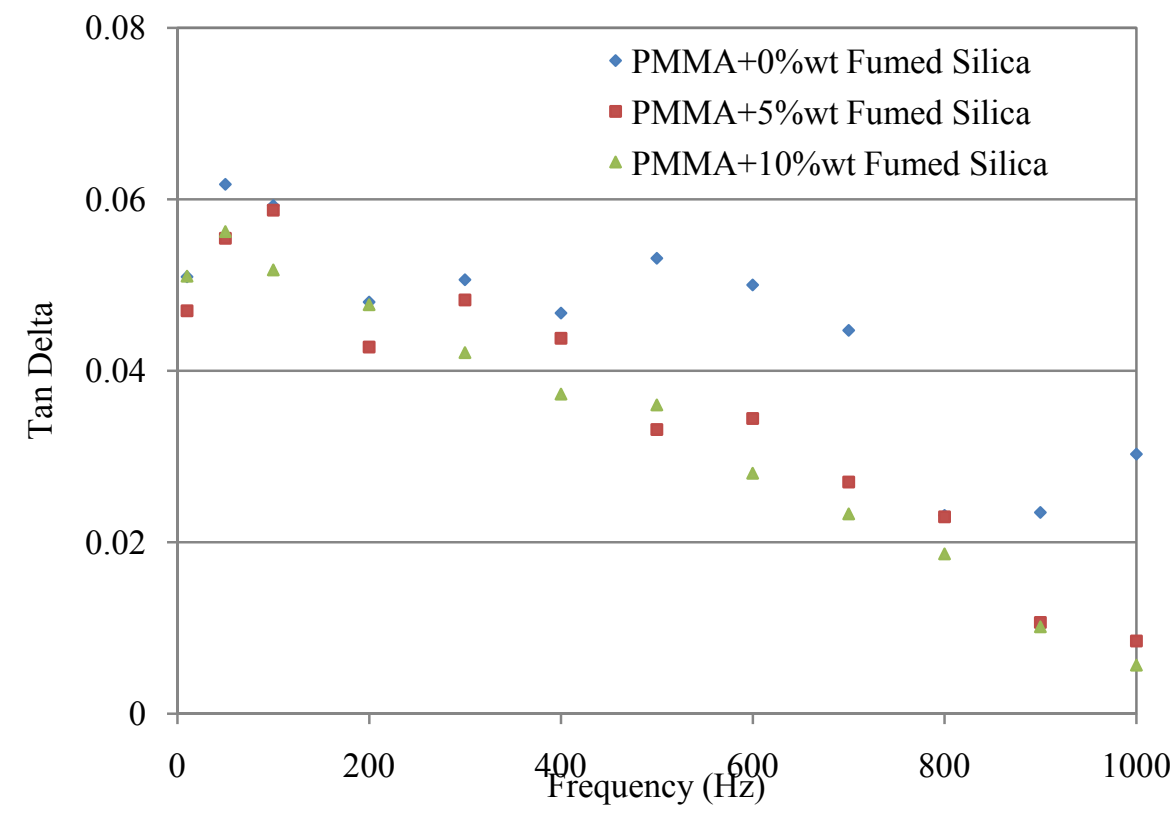

Figure 4. Measured loss tangent of Fumed silica/PMMA nanocomposites at room temperature $\left(20^{\circ} \mathrm{C}\right)$

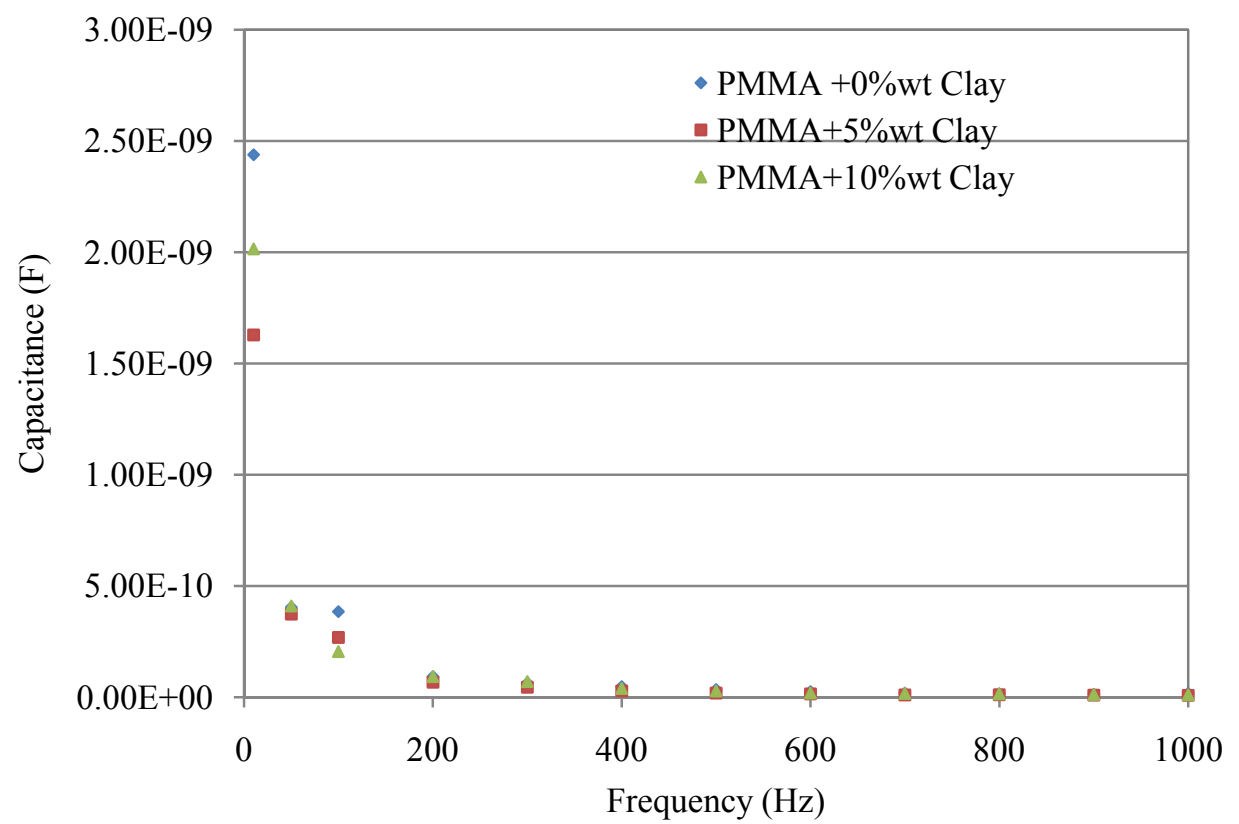

Figure 5. Measured capacitance of Clay/PMMA nanocomposites at room temperature $\left(20^{\circ} \mathrm{C}\right)$

However, figure 6 shows the capacitance versus frequency for fumed silica/ PMMA nanocomposites at room temperature $\left(20^{\circ} \mathrm{C}\right)$; the measured results shows that the decreasing capacitance with increasing the percentage of fumed silica nanofillers in the nanocomposite continuously up to certain value (10\%wt.). 


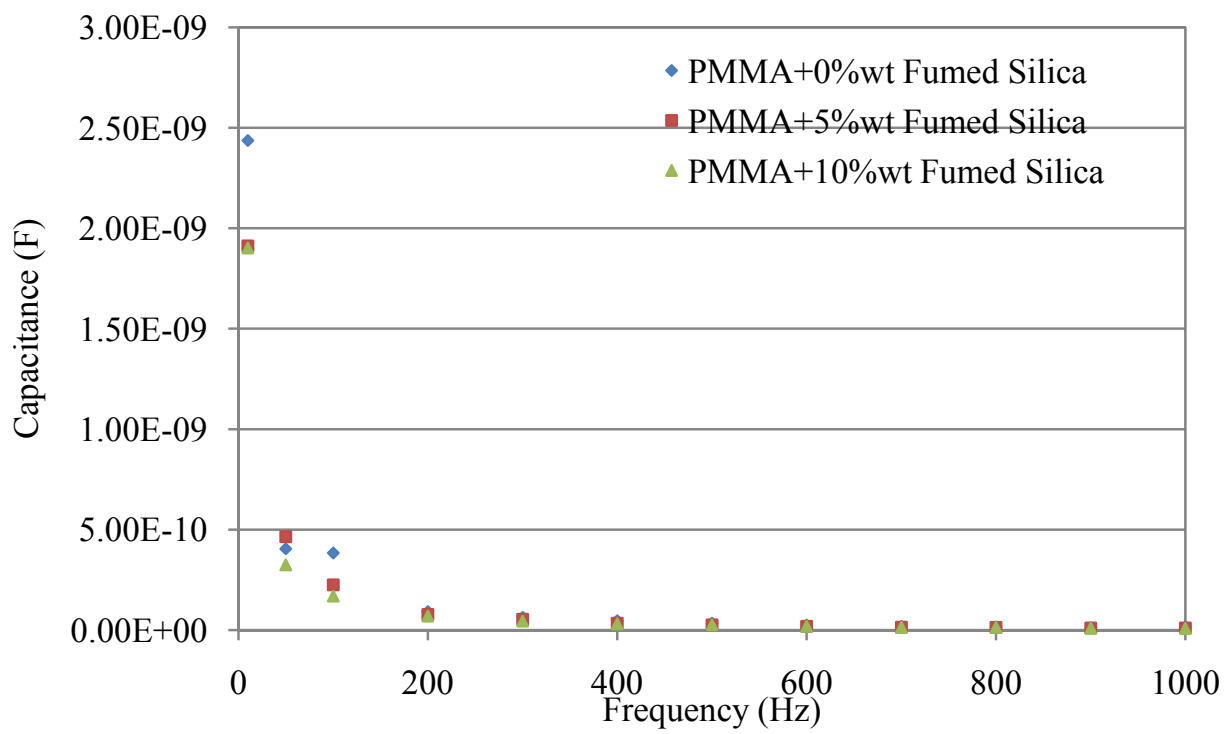

Figure 6. Measured capacitance of Fumed Silica /PMMA nanocomposites at room temperature $\left(20^{\circ} \mathrm{C}\right)$

B. Characterization of PMMA Nanocomposites at Temperature $\left(T=40^{\circ} \mathrm{C}\right)$

For medium soft temperatures, the electrical parameters of nanocomposite insulation specimens have been measured at $40^{\circ} \mathrm{C}$ and various frequencies. Thus, figure 7 shows the loss tangent of Clay/PMMA nanocomposite at $\left(40^{\circ} \mathrm{C}\right)$ that decreases with increasing clay nanofillers percentage up to certain value ( $10 \% \mathrm{wt}$.).

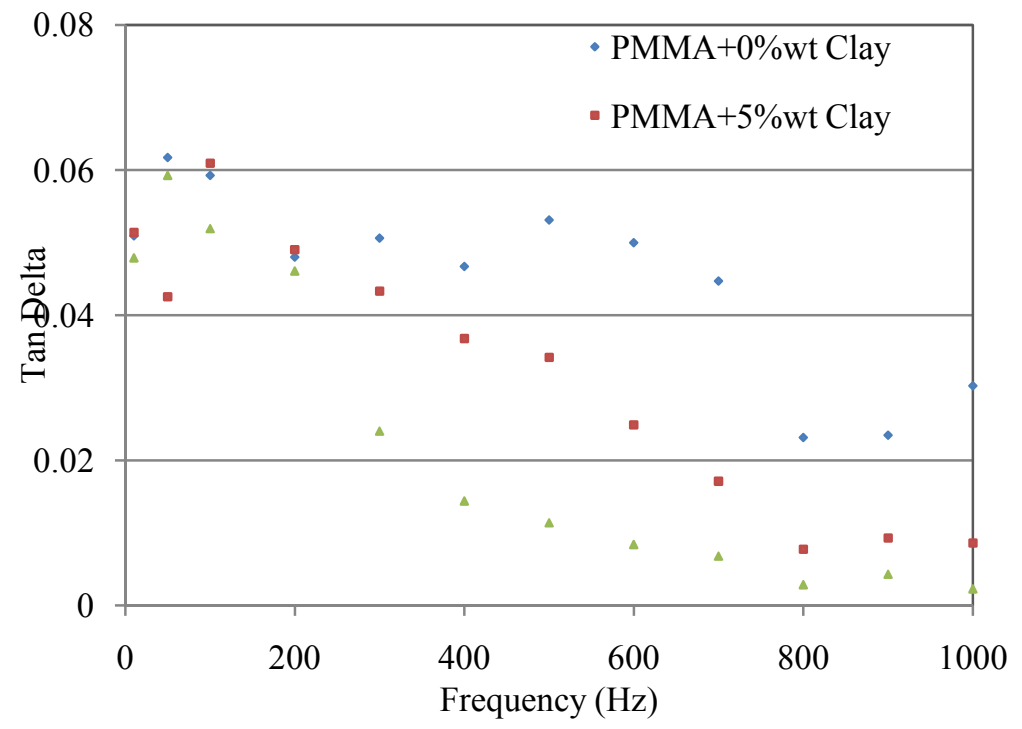

Figure 7. Measured loss tangent of Clay/PMMA nanocomposites at temperature $\left(40^{\circ} \mathrm{C}\right)$

Figure 8 shows the measured loss tangent of Fumed Silica/PMMA at $\left(60^{\circ} \mathrm{C}\right)$ that decreases with increasing fumed silica nanoparticles percentage up to certain value $(5 \% \mathrm{wt}$.) of fumed silica nanoparticles but, it increases with increasing percentage of fumed silica nanoparticles up to certain value $(10 \% \mathrm{wt}$.). On the other wise, figure 9 shows the measured capacitance of 
Clay/PMMA at temperature $\left(40^{\circ} \mathrm{C}\right)$ that increases with increasing clay nanoparticles percentage up to certain value (5\%wt.). However, the measured capacitance of Clay/PMMA decreases with increasing clay nanoparticles percentage up to certain value (10\%wt.).

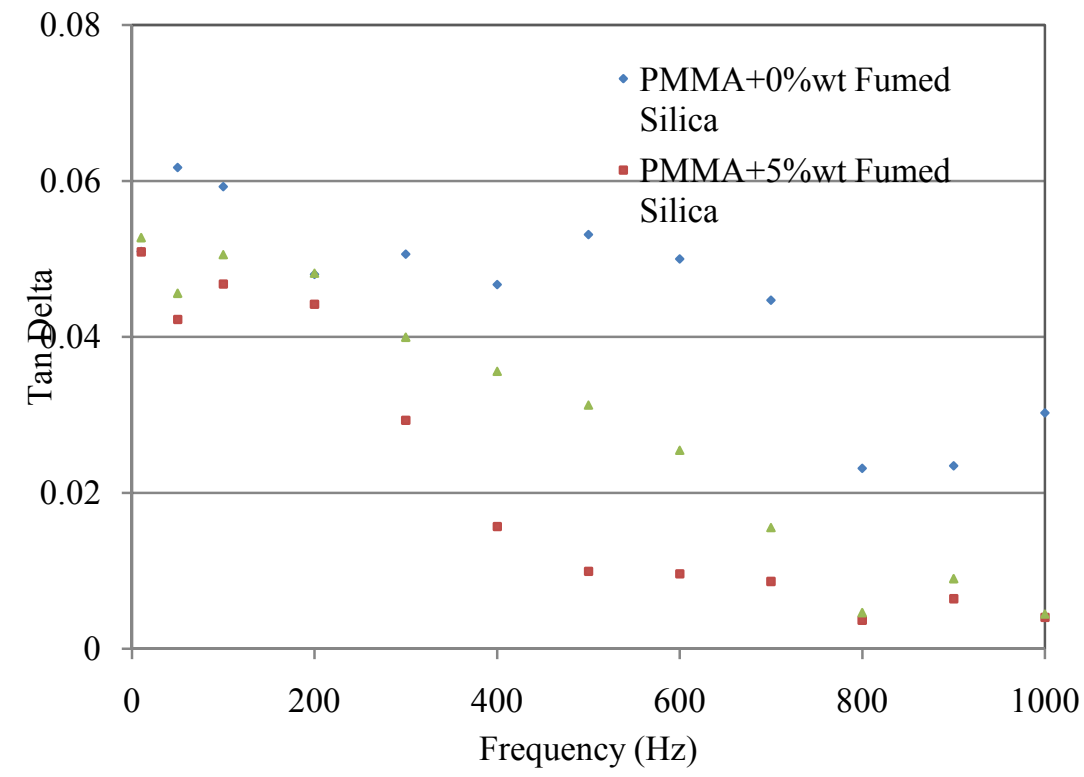

Figure 8. Measured loss tangent of Fumed Silica /PMMA nanocomposites at temperature $\left(40^{\circ} \mathrm{C}\right)$

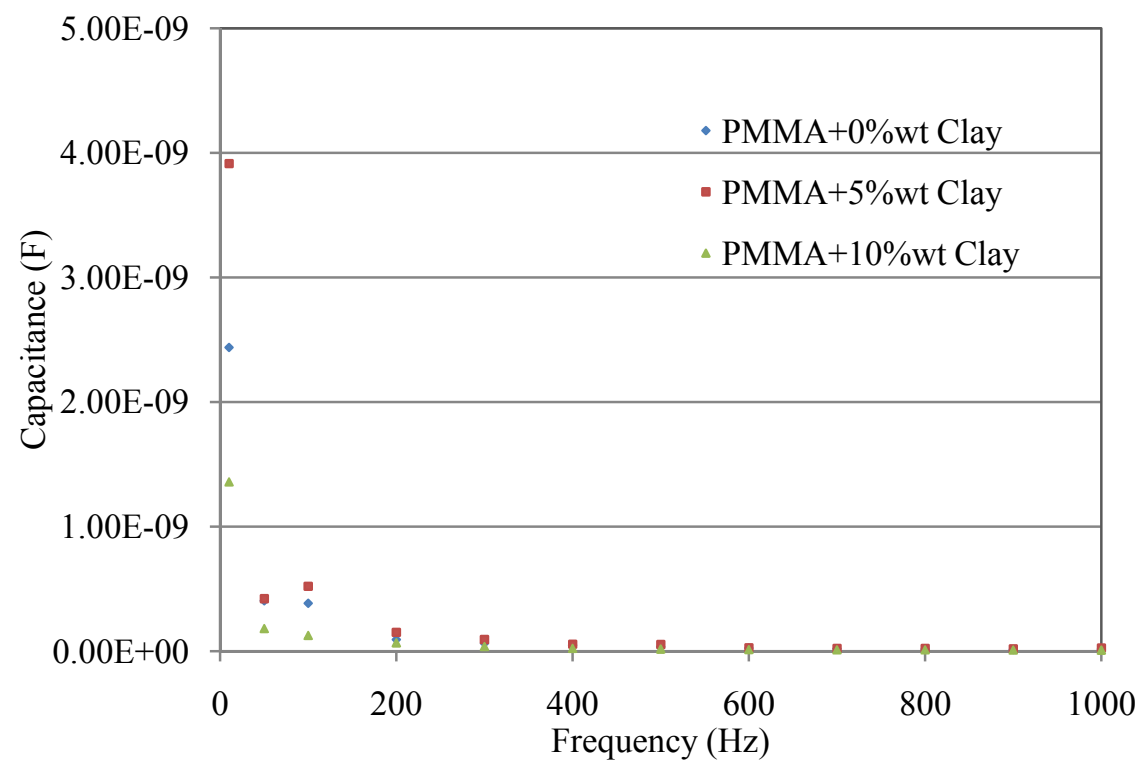

Figure 9. Measured capacitance of Clay/PMMA nanocomposites at temperature $\left(40^{\circ} \mathrm{C}\right)$

Figure 10 illustrates that the capacitance of Fumed silica /PMMA at temperature $\left(40^{\circ} \mathrm{C}\right)$ that draw decreasing with increasing fumed silica nanoparticles percentage up to certain value (5\%wt.); then, the capacitance of Fumed silica /PMMA is increasing with increasing fumed silica nanoparticles percentage up to certain value $(10 \% \mathrm{wt}$.). It is noticed that Clay 
nanoparticles increases the capacitance of Polymethylmethacrylate more than increasing fumed silica nanoparticles at the same concentration values of percentages.

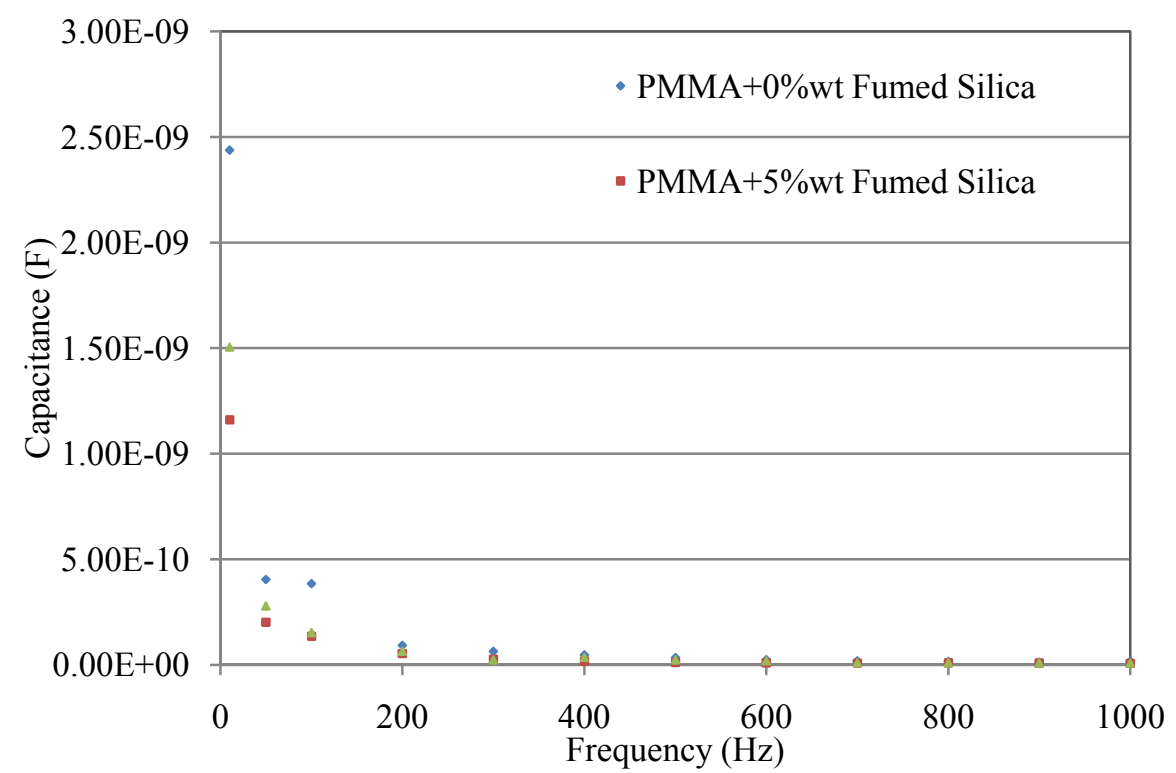

Figure 10. Measured capacitance of Fumed Silica /PMMA nanocomposites at temperature $\left(40^{\circ} \mathrm{C}\right)$

\section{Characterization of PMMA Nanocomposites at Temperature $\left(T=60^{\circ} \mathrm{C}\right)$}

Using vacuum oven and HIOKI 3522-50 LCR Hi-tester device, it can measure the electrical parameters of nanocomposite solid dielectric insulation specimens at various frequencies at high temperatures. Therefore; figure 11 shows the loss tangent versus frequency for Clay/PMMA nanocomposites at $\left(60^{\circ} \mathrm{C}\right)$. The loss tangent of Clay/PMMA nanocomposite decreases with increasing clay nanofillers percentage up to certain value (10\%wt.). Figure 12 shows the loss tangent versus frequency for Fumed Silica/PMMA nanocomposites at $\left(60^{\circ} \mathrm{C}\right)$.

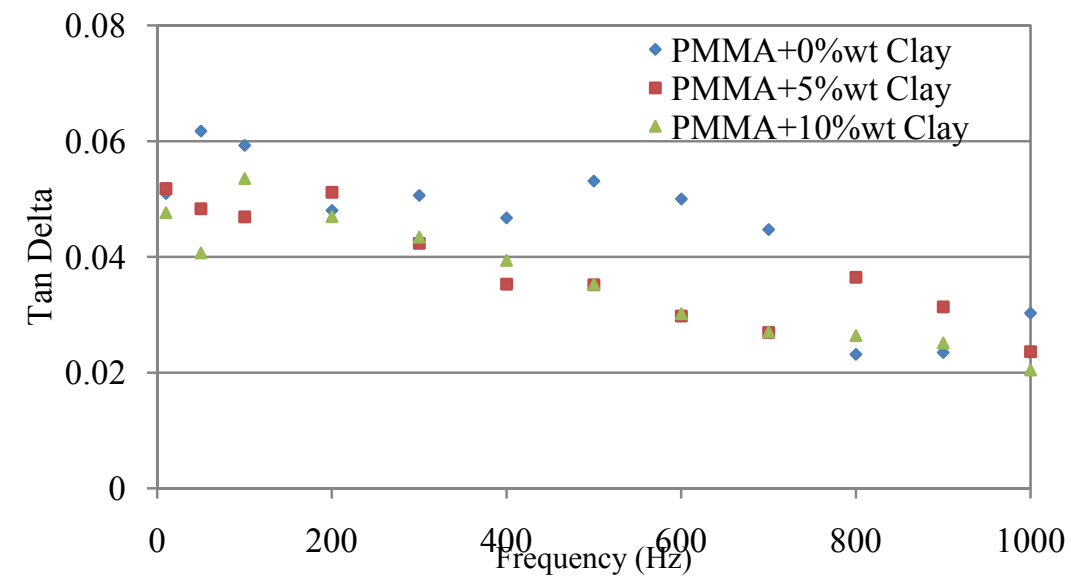

Figure 11. Measured loss tangent of Clay/PMMA nanocomposites at temperature $\left(60^{\circ} \mathrm{C}\right)$

The measured loss tangent of Fumed Silica/PMMA decreases with increasing fumed silica nanoparticles percentage up to certain value $(5 \% \mathrm{wt}$.) of fumed silica nanoparticles but, it 
increases with increasing percentage of fumed silica nanoparticles up to certain value $(10 \%$ wt.). Noting that, the dielectric loss reduction of clay and fumed silica nanoparticles at environment temperature $\left(40^{\circ} \mathrm{C}\right)$ is more effective than the environment temperature $\left(60^{\circ} \mathrm{C}\right)$.

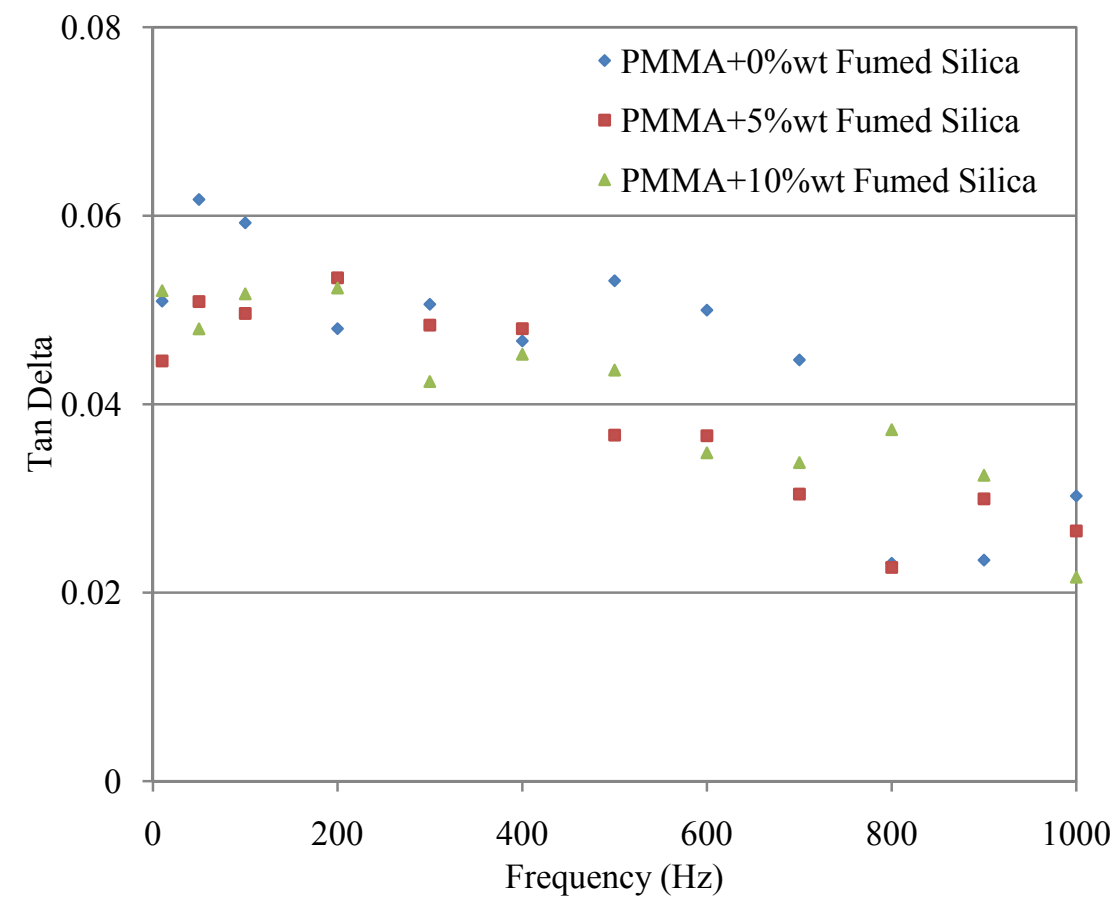

Figure 12. Measured loss tangent of Fumed Silica /PMMA nanocomposites at temperature $\left(60^{\circ} \mathrm{C}\right)$

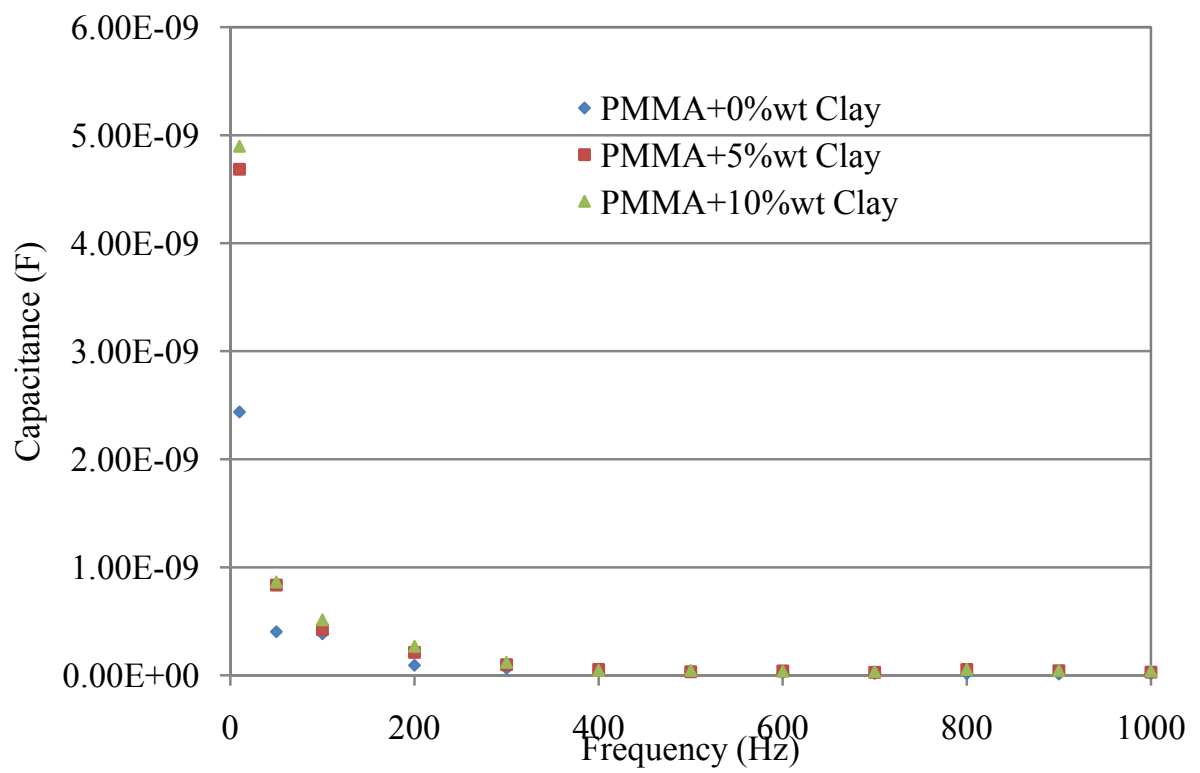

Figure 13. Measured capacitance of Clay/PMMA nanocomposites at temperature $\left(60^{\circ} \mathrm{C}\right)$ 


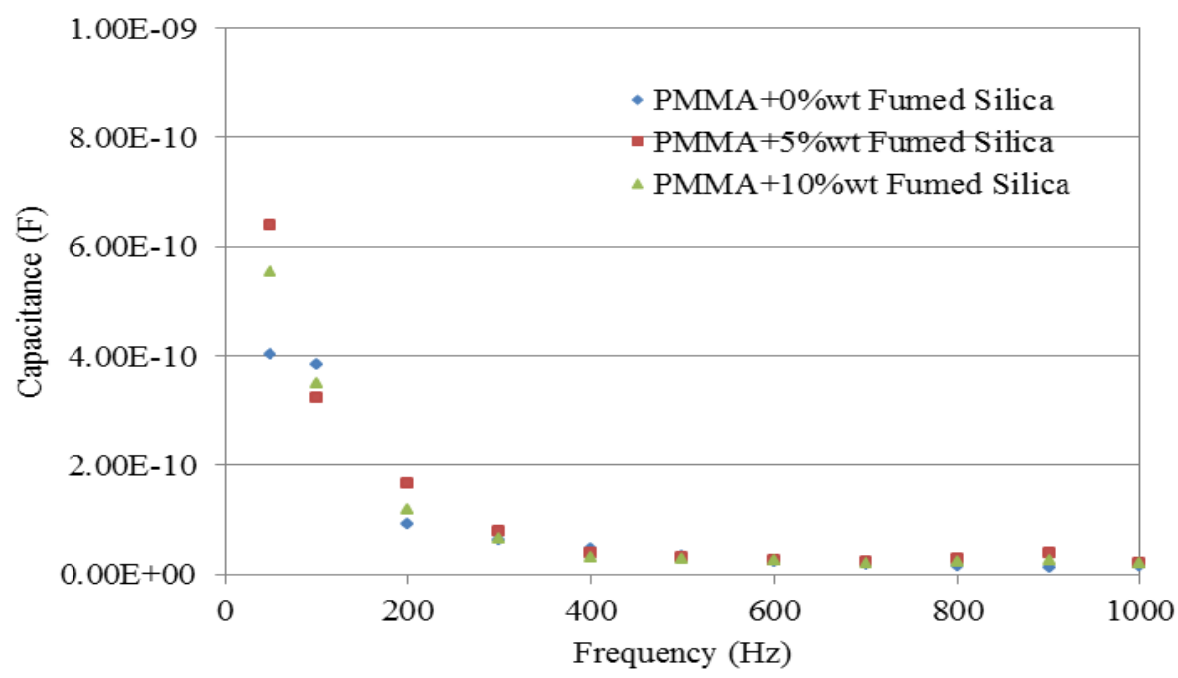

Figure 14. Measured capacitance of Fumed Silica /PMMA nanocomposites at temperature $\left(60^{\circ} \mathrm{C}\right)$

On the other wise, figure 13 shows capacitance versus frequency for Clay/PMMA nanocomposites at temperature $\left(60^{\circ} \mathrm{C}\right)$. The measured capacitance of Clay/PMMA increases with increasing clay nanofillers percentage up to certain value (10\%wt.). However, Figure 14 shows the capacitance versus frequency for Fumed silica/PMMA nanocomposites at temperature $\left(60^{\circ} \mathrm{C}\right)$. This figure illustrates that the capacitance of Fumed silica /PMMA increases with increasing fumed silica nanofillers percentage up to certain value $(5 \% \mathrm{wt}$.), then; the measured capacitance of fumed Silica/PMMA increases with increasing Fumed Silica nanofillers percentage up to certain value $(10 \%$ wt.). Noted that, Clay nanofillers increases the capacitance of Polymethylmethacrylate more than increasing fumed silica nanofillers at the same concentration values of percentages. And so, the capacitance of Polymethylmethacrylate decreases with increasing environment temperature.

\section{Comparative Layout for Commercial and Nanocomposite PMMA Industrial Materials}

In the beginning, adding fumed silica has increased permittivity of the new nanocomposite materials whatever, and adding clay has decreased permittivity of the new nanocomposite materials as shown in in table 1.

With comparing results for depicting the effect of raising concentration of clay and fumed silica nanofillers which were pointed out in figure's (3-6); the loss tangent and capacitance of new PMMA nanocomposite materials are reported for different weight concentrations of modified nanofillers concentration at room temperature $\left(\mathrm{T}=20^{\circ} \mathrm{C}\right)$. i.e the loss tangent decreases with increasing the percentage of clay and fumed silica nanoparticles percentages up to certain value $(5 \% \mathrm{wt}$.), specially, at low frequencies but it increases with increasing clay nanoparticles only up to certain value (10\%wt.), specially, at high frequencies. The measured capacitance of new PMMA nanocomposite materials at room temperature has been obvious that decreasing the capacitance with increasing percentage of clay and fumed silica nanoparticles in the nanocomposite up to certain value $(5 \% \mathrm{wt}$.), but noted that increasing clay nanoparticles percentage only up to a certain percentage (10\%wt.) has been increased the capacitance.

Thermal analysis has been appeared by raising environmental temperature up to $40^{\circ} \mathrm{C}$ and $60^{\circ} \mathrm{C}$ as shown in figure's (7-10) and figure's (11-14) respectively as follows: for medium temperatures $\left(40^{\circ} \mathrm{C}\right)$, figure's $(7,8)$ shows the loss tangent decreases with increasing clay and fumed silica nanoparticles percentage up to certain value $(5 \% \mathrm{wt}$.) due to clay and fumed silica nanoparticles on PMMA insulation materials but, the loss tangent increases with increasing 
percentage of fumed silica nanoparticles up to certain value (10\%wt.). On the other wise, figure's $(9,10)$ shows the measured capacitance increases with increasing clay nanoparticles but it is decreasing with increasing fumed silica nanoparticles percentage up to certain value (5\%wt.). It is noticed that clay nanoparticles increases the capacitance of Polymethylmethacrylate more than increasing fumed silica nanoparticles at the same concentration values of percentages. However; at high temperature $\left(60^{\circ} \mathrm{C}\right)$, the loss tangent of Clay/PMMA nanocomposite decreases with increasing clay percentage nanofillers up to a certain value $(10 \% \mathrm{wt}$.) Clay. On the other wise, The measured loss tangent of Fumed Silica/PMMA decreases with increasing fumed silica nanofillers percentage up to certain value ( $5 \%$ wt.) fumed silica but, it increases with increasing fumed silica nanofillers percentage up to certain value (10\%wt.). With respect to the measured capacitance of Clay/PMMA, it is obvious that the capacitance increases with increasing clay nanofillers percentage up to certain value (10\%wt.). Although, the capacitance of Fumed silica /PMMA increases with increasing fumed silica nanofillers percentage up to certain value (5\%wt.), then; the measured capacitance of Fumed silica/PMMA decreases with increasing fumed silica nanofillers percentage up to a certain value (10\%wt.).

\section{Conclusion}

Adding small or large percentages of different nanoparticles to PMMA has been reversed dielectric behavior characteristics gradually which depends on nature of nanoparticles structure in polymer matrix. Although, adding small or large percentages of the same nanoparticles to PMMA may be reversed dielectric behavior characteristics gradually depending on nature of accumulated distribution concentration of nanoparticles structure in polymer matrix.

At room temperature and with respect to pure PMMA characterization: addition of Clay nanoparticles decreases the permittivity and loss tangent of new PMMA nanocomposite materials but increases capacitance of the new nanocomposites. On the other hand, addition of small amount of fumed silica nanoparticles percentage to PMMA increases the relative permittivity, and loss tangent, specially, at low frequencies; but decreases capacitance of the new nanocomposites.

At medium temperatures and with respect to pure PMMA characterization: the loss tangent decreases with increasing clay and fumed silica nanoparticles percentage up to certain value (5\%wt.); then, the loss tangent increases with increasing percentage of fumed silica nanoparticles up to certain value $(10 \% \mathrm{wt}$.). On the other hand, the measured capacitance increases with increasing clay nanoparticles but it is decreasing with increasing fumed silica nanoparticles percentage up to certain value (5\%wt.). Therefore, clay nanoparticles increases the capacitance of Polymethylmethacrylate more than increasing fumed silica nanofillers at the same concentration values of percentages.

At high temperatures and with respect to pure PMMA characterization: addition of clay or fumed silica nanoparticles is still decreasing the loss tangent of new PMMA nanocomposite materials; specially, at low frequencies. But, addition of clay or fumed silica nanoparticles on PMMA increases capacitance, specially, at low frequencies. Noting that, adding clay nanofillers increases capacitance of PMMA more than increasing fumed silica nanofillers in PMMA at the same percentages.

\section{Acknowledgements}

The present work was supported by the Science and Technology Development Fund (STDF), Egypt, Grant No: Project ID 505.

\section{References}

[1] M. A. Jothirajan, T. Mathavan, A. Ramasubu, "Thermal Properties of PMMAMontmorillonite Clay Nanocomposite" Journal Nanoscience and Nanotechnology, Vol. 6, $1-4,2006$. 
[2] R. R. Prakash, S. Pandiarajan, P. Venkatesh, and N. Kamaraj, "Performance analysis of PMMA - TiO2 nanocomposite dielectrics," in Emerging Trends in Electrical and Computer Technology (ICETECT), 2011 International Conference on, 2011, pp. 46-49.

[3] X. Sun, X. Chen, X. Liu, and S. Qu, "Optical properties of poly(methyl methacrylate)titania nanostructure thin films containing ellipsoid-shaped titania nanoparticles from exsitu sol-gel method at low growth temperature," Applied Physics B: Lasers and Optics, pp. 1-8, 2010.

[4] L. N. Ismail, F. A. Ahmad, H. Zulkefle, M. M. Zaihidi, M. H. Abdullah, S. H. Herman, U. M. Noor, B. Mahmood, and M. Rusop, "Optical Properties and Surface Morphology of PMMA: TiO2 Nanocomposite Thin Films," Advanced Materials Research, vol. 364, pp. 105-109, 2012.

[5] L. N. Ismail, S. A. Farahiyah, Z. Habibah, S. H. Herman and M. Rusop, "Dielectric and physical properties of PMMA: TiO2 thin films by varying TiO2 concentration" IEEE Symposium on Humanities, Science and Engineering Research, pp. 259-262, 2012.

[6] T. Tanaka, G.C. Montanari and R. Mulhaupt, "Polymer nanocomposites as dielectrics and electrical insulation-perspectives for processing technologies, material characterization and future applications", IEEE Trans. Dielectr. Electr. Insul., Vol. 11, pp. 763-784, 2004.

[7] M. Roy, J. K. Nelson, R. K. MacCrone, L. S. Schadler, C. W. Reed, R. Keefe and W. Zenger, "Polymer Nanocoposites dielectrics - the role of the interface", IEEE Trans. Dielectr. Electr. Insul., Vol. 12, pp. 629- 641, 2005.

[8] P. Maity, S. Basu, V. Parameswaran and N. Gupta, "Surface Degradation Studies in Polymer Dielectrics with Nano-sized Fillers", IEEE Int. Conf. on Properties and Application of Dielectr. Material, Bali, Indonesia, pp. 171-174, 2006.

[9] P. Maity, S. Basu, V. Parameswaran and N. Gupta, "Degradation of Polymer Dielectrics with Nanometric Metal-oxide Fillers due to Surface Discharges", IEEE Trans. Dielectr. Electr. Insul., Vol. 15, pp. 52-62, 2008.

[10] P. Maity, S. V Kasisomayajula, V. Parameswaran, S. Basu, N. Gupta, "Improvement in Surface Degradation Properties of Polymer Composites due to Pre-processed Nanometric Alumina Fillers" IEEE Transactions on Dielectrics and Electrical Insulation Vol. 15, No. 1, pp. 63-72; February 2008.

[11] Ramirez, Sh. Jayaram, E. A. Cherney, M. Gauthier, and L. Simon, "Erosion Resistance and Mechanical Properties of Silicone Nanocomposite Insulation" IEEE Transactions on Dielectrics and Electrical Insulation Vol. 16, No. 1, pp. 52-59; February 2009

[12] T. Tanaka, G. C.Montanari and Mulhaupt, "Polymer Nanocomposites as Dielectrics and Electrical Insulationperspectives for processing technologies, Material characterization and Future Applications", IEEE Transactions on Dielectrics and Electrical Insulation, Vol. 11, No.5, pp. 763-784, October 2004.

[13] T. Tanaka, "Dielectric Nanocomposites with Insulating properties", IEEE Transaction Dielectrics \& Electrical Insulation, Vol. 12, No.5, pp. 914-928, 2005.

[14] Thabet, and Y. A. Mubarak, S. Ismail, "Exponential Power Law Model for Predicting Dielectric Constant of New Nanocomposite Industrial Materials" International Conference On Materials Imperatives in the New Millennium, (MINM 2010), Cairo, Egypt, 29Nov.-2Dec. 2010.

[15] Thabet, and Y. A. Mubarak, "Novel Nanocomposite Insulation Materials for the Enhancing Performance of Power Cables" 21st International Conference and Exhibition on Electricity Distribution, “CIRED2011”, Frankfurt, Germany, 6-9 June 2011.

[16] Thabet, "Influence of Cost-Less Nanoparticles on Electric And Dielectric Characteristics of Polyethylene Industrial Materials" International Journal of Electrical Engineering and Technology (IJEET), ISSN 0976 - 6545(Print), ISSN 0976 - 6553(Online), Volume 4, Issue 1, pp. 58-67, (C IAEME Jan.- Feb. 2013.

[17] Thabet, "Experimental Investigation on Thermal Electric and Dielectric Characterization for Polypropylene Nanocomposites Using Cost-fewer Nanoparticles" International 
Journal of Electrical Engineering and Technology (IJEET), ISSN 0976 - 6545(Print), ISSN 0976 - 6553(Online), Volume 4, Issue 2, pp. 1-12, (C) IAEME March-April 2013.

[18] O. Gouda, A Thabet, Y. A. Mubarak, and M. Samir, "Nanotechnology Effects on Space Charge Relaxation Measurements for Polyvinyl Chloride Thin Films" International Journal of Electrical Engineering and Informatics (IJEEI), Engineering and Technology, Vol:6 No:1, pp. 1-12, March, 2014.

[19] G. D. Wilk, R. M. Wallece, and J. M. Anthony, "High-k gate dielectrics: Current status and materials properties considerations", J. Appl. Phys., Vol. 89, pp. 5243-5275, 2001.

[20] I. Kingon, J. P. Maria, and S. K. Steiffer, "Alternative Dielectrics to Silicon Dioxide for Memory and Logic Devices", Nature (London), Vol. 406, pp. 1032-1038, 2000.

[21] R. C. Advincula, "Surface initiated polymerization from nanoparticle surfaces", $J$. Dispersion Sci. Technol., Vol. 24, pp. 343-361, 2003.

[22] S. S. Ray and M. Okamoto, "Polymer/layered silicate nano-composites: a review from preparation to processing", Prog. Polym. Sci., Vol. 28, pp. 1539-1641, 2003.

[23] Y. Rao, and C. P. Wong, "Material characterization of a high-dielectricconstant polymerceramic composite for embedded capacitor for RF applications", J. Appl. Polym. Sci., Vol. 92, pp. 2228-2231, 2004.

[24] S. O. Brian, L. Brus, and C. B. Murray, "Synthesis of Monodisperse Nanoparticles of Barium Titanate: Toward a Generalized Strategy of Oxide Nanoparticle Synthesis", J. Am. Chem. Soc., Vol. 123, pp. 12085- 12086, 2001.

[25] P. Murugaraj, D. Mainwaring, and N. Mora-Huertas, "Dielectric enhancement in polymer-nanoparticle composites through interphase polarizability", J. Appl. Phys., Vol. 98, pp. 054304 - 054309, 2005.

[26] Q. M. Zhang, H. Li, M. Poh, F. Xia, Z.-Y. Cheng, H. Xu, and C. Huang, “An All-Organic Composite Actuator Materials with a High Dielectric Constant", Nature (London), Vol. 419, pp. 284-287, 2002.

[27] N. Shi and R. Ramprasad, "Local Properties at Interfaces in Nanodielectrics: An ab initio Computational Study" IEEE Transactions on Dielectrics and Electrical Insulation Vol. 15, No. 1, pp. 170-177; February 2008.

[28] N. L. Dao, P. L. Lewin, I. L. Hosier and S. G. Swingler, "A Comparison between LDPE and HDPE Cable Insulation Properties Following Lightning Impulse Ageing" IEEE, International Conference on Solid Dielectrics, Potsdam, Germany, July 4-9, pp.1-4, 2010.

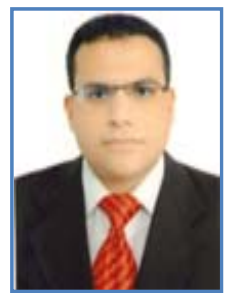

Ahmed Thabet was born in Aswan, Egypt in 1974. He received the B.Sc (FEE) Electrical Engineering degree in 1997 and M.Sc (FEE) Electrical Engineering degree in 2002 both from Faculty of Energy Engineering, Aswan, Egypt. PhD degree had been received in Electrical Engineering in 2006 from El-Minia University, Minia, Egypt. He joined with Electrical Power Engineering Group of Faculty of Energy Engineering in Aswan University as a Demonstrator at July 1999, until; he held Associate Professor Position at October 2011 up to date. His research interests lie in the areas of analysis and developing electrical engineering models and applications, investigating novel nano-technology materials via addition nano-scale particles and additives for usage in industrial branch, electromagnetic materials, electroluminescence and the relationship with electrical and thermal ageing of industrial polymers. Many of mobility's have investigated for supporting his research experience in UK, Finland, Italy, and USA ...etc. On 2009, he had been a Principle Investigator of a funded project from Science and Technology development Fund "STDF" for developing industrial materials of ac and dc applications by nano-technology techniques. He has been established first Nano-Technology Research Centre in the Upper Egypt (http://www.aswan.svu.edu.eg/nano/index.htm). He has many of publications which have been published and under published in national, international journals and conferences and held in Nano-Technology Research Centre website. 